\title{
Technological Aspects in Construction Safety with Applicability to Hazards in India
}

\author{
Abhay Malik, Sripadma Sanjiv E, Kranti Kumar Myneni
}

\begin{abstract}
In India as well as in the global scenario Construction industry is viewed as one of the largest employment and economy generating sector, which in turn increases the probability of hazard \& risks in the industry. Many developed countries have adopted technological interventions as safety measures to minimize these risks. Comparing to the safety scenarios in Indian construction sites, the hazards are twenty times higher than in United Kingdom and thirty times than in U.S.A. In developing countries like India, the completion of the project is given more importance than the safety rules and regulations. Most of the hazards in Indian Construction site arises due to the carelessness of human beings, improper safety trainings, and lack of technology as well as communication. This study aims to find the applicable technological tools that can be utilised for ensuring safety at construction sites. The study also gives the information about various hazards and applicable technological tools for a particular kind of hazard. The study utilizes the data from the existing literature available with OSHA (Occupational Safety and Health Administration) and research papers \& journals to find the most commonly occurring hazards and also the technological tools that are existing in the market and employed to cope with the identified hazards. The data collected is then analysed and on basis of the hazard identification, a comprehensive list of technological tools used for the preventive or safety measures for that particular hazard at construction site are formulated. The findings of this research will be helpful to produce a better safety management plan for construction sites in India.
\end{abstract}

Keywords: Construction Industry, Hazards, Safety, Technologies

\section{INTRODUCTION}

Construction industry is viewed as the most perilous industries amongst all other industries prevailing in the world. There are number of accidents, injuries and deaths around the world during the construction works. Despite the stronger implementation of safety rules and regulations by different- different Governments to their respective countries around the world, there is no significant reduction has been noted in the construction accidents [40]. Due to these conditions, huge amount of money, material, manpower \& machinery, etc. are used and wasted. The timely completion or timely delivery of the project are being considered as the sole priority by any construction practitioner or contractor or company.

Revised Manuscript Received on June 12, 2020.

* Correspondence Author

Abhay Malik, Department of Architecture, School of Planning and Architecture, Vijayawada, Andhra Pradesh, India. Email: abhaymalik58@gmail.com

Sripadma Sanjiv E, Department of Architecture, School of Planning and Architecture, Vijayawada, Andhra Pradesh, India. Email: sripadmasanjiv@gmail.com

Kranti Kumar Myneni*, Department of Architecture, School of Planning and Architecture, Vijayawada, Andhra Pradesh, India. Email: kranti.myneni@spav.ac.in

(c) The Authors. Published by Blue Eyes Intelligence Engineering and Sciences Publication (BEIESP). This is an open access article under the CC BY-NC-ND license (http://creativecommons.org/licenses/by-nc-nd/4.0/)
Following agriculture, construction is the second largest economy generating activity in India [42]. The Indian construction industry accounts for the highest number of deaths around the globe due to construction accidents compared to the other nine sectors [53], [54].

In Indian scenario, the construction sector is the second largest sector after agriculture which provides jobs to the approximately 465 million workers and contributing nearly $12 \%$ of the national GDP [57] [63]. The construction industry accounts for the $40 \%$ to $50 \%$ of Indian Capital expenditures like highways, roads, railways, etc. [40]. According to the British Safety Council study which reveals that Indian construction workers enjoy no legal protection and their on-site death rate is 20 times higher than UK and 30 times higher than USA [69]. The fatality rate in construction industry is 5 times higher than manufacturing industry and the risk of crucial injuries is 2.5 times higher as per stated in yet another study by British Safety Council [69].According to the survey conducted by International Labour Organization, 38 construction workers die every day working on construction in India (ILO, 2014). [40]According to the compilation of annual statistics by Government of India, there have been 121 deaths in the FY2018 reported by only 13 biggest companies in India and unreported deaths are unknown [65]. According to the British Safety Council, it is estimated that there are 48000 construction work related deaths takes place in India every year while there were 144 deaths in UK. [69]

As construction industry in India is more labour intensive due to which there is a high increase in construction deaths and also the lesser technological interventions, there is an urgent need of adopting new and emerging technologies at construction sites, for safety of construction workers. In Indian aspect, it is estimated that from the strong workforce of 465 million, around $80 \%$ of the workforce are not protected by the existing health and safety legal structure [69].It is very well known fact that construction sector always hesitates in adopting new technologies as there is lack of knowledge or information regarding technology, thedilemmain using new technologies, corresponding benefits and cost of adapting the them. But use of these technological interventions is deemed to be a potentway to ensure security and safety at the construction sites. Various technologies like sensor based technology, information communication technology, radio frequency identification technology and virtual reality are used to ensure safety at site in global scenario. Kim and Cho said that technologies are an alternative ways to improve and ensure safety at construction site [67]. It is not possible to eliminate human mistakeson site by using technology butit is aneffective way to reduce the risk by training the concerned person at site and to create a safety friendly environment at the site.

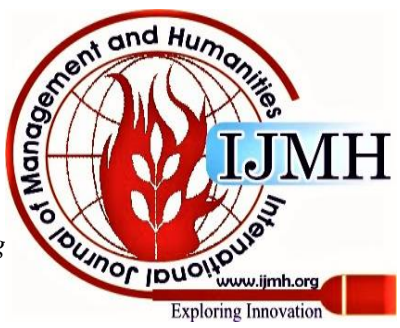


The study is conducted in context to contribute in- depth investigation of the hazards or risks and the technologies used for the particular kind of hazard and providesa scope for other researchers and practitioners to contribute in filling the gaps between the theory andthe practical advancements. The remainder of this study gives the reader to know about the type of technologies that are applicable to particular hazard or one technology applicable to many hazards.

\section{METHODOLOGY}

Construction sites are susceptibleto hazards which causesfatalities and injuries. This papers uses an integrated review of literature, which is a comprehensive methodological approach to compiles data from the literature sources to conclude the applicable technologies to the particular hazards. This methodology is designed to comprehend safety facets in construction industryusing technology, in an explanatory manner.

The paper adopts the methodological approach and tries to assemble the applicable technologies on hazards in construction sites. The process of database construction or methodology is shown in below given figure 1 :

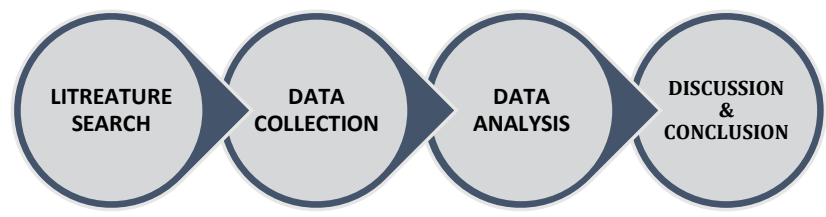

Fig. 1: Methodology

Literature review calls for anextensive data collection related to thetopic. The utilization of online database and technical papers helps in achieving this. The crucialdata collection method used for this study is through the reviewof approximately 60 research papers, 14 online links, journals and case studies. The present study was conducted to establish and to assemble the safety technologies on particular type of hazards that are faced in construction sites by workers.

\section{LITERATURE REVIEW}

In global context, the construction is considered to be the most dangerous and threating industry. The condition of safety around the globe is in very bad state. The standard framework to adopt norms and technologies for safety is pathetic for developing countries. In India, the importance of safety to construction sites is totally ignored to complete the project timely, keeping the life of workers at stake or risk. Even though the construction industry, plays a major role in India economy and is considered as the booming industry, no adequate steps areare undertaken by Government to enforceproper rules and regulations in the sites to ensure safety of the workers. According to Hale (2009), the basis of selecting goodindicators for safety performance are sensibility,validity, openness to bias, cost effectiveness, representativeness and reliability [49]. In India, there is an estimate of 465 million people employed to construction and there is shortage of skilled manpower [63] [69]. It is also inferred from previous studies that there is a hesitation in adopting existing and new technologies in construction sector which leads to the unforeseen conditions like safety issues, unhealthy environment at site, unaware about the hazards, etc. at the construction sites which ultimately results in loss of life's. This study allows the reader to come across the various types of hazards at sites and the applicable technology to control that in particular.

\section{A. Construction Hazards and Its Causes}

Most of the hazards in construction industry are caused due to the unsafe behaviour of victims, unsafe act of co-workers, unsafe conditions created by the workers, unsafe condition created by use of improper machineries or combination of the above [1]. Careless or unethical provisions provided by the contractor in order to save the cost along with lack of proper training and awareness among the workers add on to the causes of these hazards.

The Occupational Safety and Health Administration (OSHA) have recognized four hazards as the major cause of causalitiesin construction industry. They are Falls, Struckby, Caught-In or -Betweenand Electrical Hazards. OSHA has named these as "Fatal Four" [2].

\section{a. Fall Hazards}

Falls are the most common accidents in construction industry. Any incident that can cause the worker to lose their balance or lose their bodily support and results in a fall at the worksite is called a fall hazard. All the surfaces utilized for walking and working is deemed as a potential for fall hazards. Fall hazards are the one of the major hazard that workers are subjected to on a daily basis irrespective of worksite. Falling from heights are the major cause of accidents at all the construction sites, whilst also falls i.e. slips and trips are among the leading causes of injuries at the same level[3]. Examination of the information shows that falls have certain properties that might be of help in contriving precautionary methods. The construction industry, OSHA and a number of specialists have been working hard to define counter-measures to prevent falls. Be that as it may, a few measures don't fill in just as anticipated [4].

\section{b. Struck-By Hazards}

Struck- by Hazards are those that causes injuries that are produced by forcible contact or impact of an object or piece of object on a person. Here the word struck refers to the event in which the ramming of the object is the lone cause ofthe fatality. [5]Struck- by hazards are classified again as

\section{1) Struck-by flying object}

These are the hazards that are caused when something is hurled, thrown or is catapultedoverthe space. It can be caused by a piece of material, tool or machine, which strikes the worker and result in injury. It is also considered as a flying objected hazard if an object is forced to be thrown out by subjecting it to high pressure using a tool or equipment such as a nail gun[5]

\section{2) Struck-by falling object}

If the casualty is caused by a source that is falling from anelevation it is termed as falling object hazard. It also includes events in which the person is getting crushed, 
pinned or caught under the falling objects, other than collapse of structure or building material. [5]

\section{3) Struck-by swinging object}

These are those that result in injuries caused by the objects that has the potential to swing and strike workers. This also includes events where injuries are causes by the retracting motion of objects due to which the workers can be struck by.

It occurs mainly due to the swinging and twisting motion of materials that are caused to its manual liftingThe position of the worker and the force behind the load decides the extent of injury. [5]

\section{4) Struck-by rolling object}

If the hazards are caused by the rolling or sliding motion if an object at the same level where workers are located, then it is categorised as Struck-by rolling object hazards. The fatalities caused by the running over of a moving vehicle without being caught under it can also be grouped under the same. [5]

\section{c. Electrocution}

The causalities caused by the exposure to a fatal amount of electrical energy are called electrocution hazards. It is a legal workplace hazard that can cause workers: electrocution. Burns from electricity can be of 3 types: Electrical, Arc/ Flash or Thermal Contact.

2) Electrification: Most lethal and causes death. Caused due to exposure to lethal amount of electricity.

3) Shock:Reflex reaction to the surge of electricity through the body.

4) Arc Flash/Blast: An arc flash is unexpected exposure of electrical energy through air where there is a strong voltage difference and there is a disruption between the conductors

5) Fire: Most electrical fires are linked to problems with "fixed wiring" such as faulty power outlets and outdated wiring. Troubles with cables (such as extension and cables), connectors and switches can trigger electrical fires.

6) Explosions: An explosion can happen when a volatile combination of material in the air is ignited by electricity. [6]

\section{d. Caught-In or-Between}

If the injury caused is more due to the crushing between objects, then it is called as being caught-in or caughtbetween hazards.

Events that should be classified as caught include:

1) Cave-ins (trenching)

2) To be pulled or trapped in machinery and appliances

3) To besqueezed or crushed between rolling, moving or shifting objects such as semi-trailers or between a truck frame and hydraulic bed that is lifting[7]

According to the statistics provided by OSHA, these "Fatal Four" were responsible for more than half i.e., $58.6 \%$ of the construction workers death in 2018. Of this 58.6\%, 33.5\% was caused by Falls, $11.1 \%$ was caused by Struck by
1) Burns:It is the most common injury caused due to

Objects, 8.5\% due to Electrocution and 5.5\% by Caught-In or -Between [2]. OSHA along with the construction industry stakeholders all around the world have been working on the safety precautions and norms to be followed to reduce these hazards. Many new Technological interventions are also being developed and currently in use that are helping in the prevention of these hazards.In addition to developing countries such as India, the construction sector is often regarded as riskier than in developed countries such as United Stated and the United Kingdom. According to global statistics, the death and disability rate for accidents are three and two times higher than the average for other industries

\section{B. Technology Tools in Safety}

The gradual increase in the reliance of construction industry on the technological innovations for safety management have given way for the growth of literature on safety management using technology. Number of literature on work sitesafety technologies are now available which has helped us to gain an insight on the different options available to mitigate the dangers in construction sites using technology. These researches have not only made the construction stakeholders aware of the new tools developed but also said how to use them to prevent work zone hazards. With the help of this study it is been tried to develop a comprehensive list of technical tools available in the construction industry and also tried to identify the tools that can effectively be used in prevention of the fatal hazards mentioned in previous section. For which literature study through the review papers as well as research papers are been used.

From the literature review,some of the sensors used for the working of these technologies are: Infrared, Magnetometer, Radar, RFID, Sonar, Bluetooth , GPS , Accelerometer, Gyroscope, Ultrasound, UWB, Wi-Fi, Capacitive sensor, EKG/ECG , EMG, GSR, Humidity sensor, Light sensor, Noise sensor, Pressure sensor, Temperature sensor [9,10]. Some studies shows that the integration and combination of many of these technological tools can also effectively prevent hazards in construction sites. For example, if we could combine the proximity tracking system, physiological status monitoring systems, real time location tracking systems and similar technological interventions and implement them in the Personal Protective Equipment or in form of wearable technology, it would me more effective to collect the data on site and alert the stakeholders before the accidents. [1, 10, 18]. The following technologies are been identified from the previous available studies and online data:

\section{1) Smart Vests}

Smart Vest are the type of wearable devices that monitors construction workers health in real time. The sensors attached to the vest helps to measure body temperature and heart rate of the workers. The identified data is sent to the wirelessly connected smartphone application which alerts and allows the user to take necessary and precautionary actions to any abnormalities. [23]

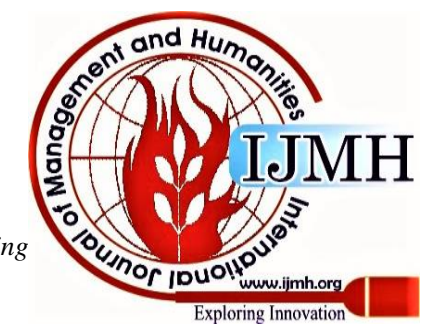




\section{2) Personalized Safety Instruction System}

Personalized safety instruction system uses the smartphone app which alert workers to the possible consequences or dangers in different activities and appropriate measures to be taken under various circumstances. In this system, one has to register first on the provided smartphone app so that their task can be recognised by the system. Whenever an individual enters the work area, the device captures and records the location of employees in real time. After processing the data, the feedback information system will deliver the safety protocols to the worker. The program does not star operating until the user has entered the site[8]

\section{3) Unmanned Arial Vehicles}

Unmanned Arial Vehicles are mainly used for the control of construction operations and work site management, for the inspection of construction sites, for assessment of structural integrity and management. [56]

\section{4) Dynamic Speed Display Device}

A Dynamic Speed Display Device (DSDD) measures the speed of approaching vehicles and communicates the speed to drivers on a digital display. DSDDs are typically used to encourage drivers that are travelling faster than the speed limit to reduce their speed in neighbourhoods and in construction zones. [59]

\section{5) Delineation Devices}

It is a type of traffic control device used to provide delineation. It provides the driver with visual or tactile information to help them prepare and monitor the position, speed or direction of their vehicle.[25] [58]

\section{6) Proximity Warning Systems}

The Proximity Warning Systems (PWSs) are processed to create an emergency alarm in response to the sensing of a foreign object in the immediate vicinity of a device.They are used in industries, such as underground mining and rail sectors to raise awareness of workers' hazards.[28] [66]

\section{7) Blind Spot Detection System}

A blind spot detection system is the type of laser sensor and displaying system that finds the equipment's blind spots easily and rapidly and also finds through $3 \mathrm{D}$ analysing, the point cloud data from a laser scan inside the equipment cab. BSDS's allows to alert for vehicle to person, alert for crossing and walkway, personal access control, vehicle access control, asset protection and in-sight data analysis. [28] [29] [66]

\section{8) Real Time Location Tracking Systems}

A real time location tracking technique has been implemented to enhance the security of multiple workers at confined work sites. The RTLT system can track the location and activity of several employees in real time. [11] [26]

\section{9) Body Posture Detection Systems}

The term posture is used to describe how a person's body is positioned when they are either sitting, standing, or lying down. A posture monitoring system would comprise of a sensing module that is attached to someone's upper or lower back and could monitor the position of the spine. The sensing module would need to be self-powered, compact, and robust to be competitive in the market. It would also have to be able to transmit real-time data to a smartphone or control hub. [27]

\section{0) Physiological Status Monitoring systems}

The physiological monitoring device requires a sensor module to be worn by the worker. A dock will be attached to the sensor module and it contains an electrically wired connection to the sensor. The portable transmitter unit is installed in the dock, which includes a transmitter and a removable connector component, which can be made with dock connector to route the data of the sensor to the transmitter [64] [66]

\section{1) Environmental Sensing Systems}

Environment Sensing Devices use sensors to monitor a variety of discomforts such as air quality, carbon monoxide, capacitance, colour, humidity, gas leakage, atmospheric pressure, temperature, light etc.The capacitive sensor has been used in various systems aa a stud finder, a liquid level indicator or a proximity detector. Various sensing concepts have been built into the polyimide foil, such as capacitive and resistive indicators for the detection of many types of environmental indicators, including temperature, humidity, reducing and oxidising gases and volatile organic compounds (VOCs).Intelligent RFID tags for environmental monitoring are needed for these plastic foil sensors. [30] [66]

\section{2) Micro Electro Mechanical Systems}

Micro Electro Mechanical Systems (MEMS) technology encourages the production of miniature and low powered inertial sensors, accelerometers and gyroscopes for the study of human activities, relying on kinematics. MEMS are small, integrated devices or technologies which blend electrical and mechanical components. They range in size from the sub-micrometre level to the millimetre level and any number from a few to a million can be represented in this system. These systems can detect, monitor and enable micro-scale mechanical processes and operate individually or in clusters to deliver impacts on a macro scale[55]

\section{3) ANT+ Wireless Technology}

ANT+ is a wireless network sensor framework developed to help the communication among self-propelled devices in an expandable network environment, to facilitate the collection, automatic transmission and monitoring of sensor data for tracking of all personal wellness information.ANT+ allows devices to collaborate and create ecosystems by introducing user profiles that are ANT+ protocol specifications. In ANT+, many applications can run concurrently using different sensors. ANT+ technology is used to track the various types of communication devices that are available for use in protection from hazards. [30] [66]

\section{4) 4D- BIM and Virtual Reality Systems}

4D-BIM (four-dimensional building information modelling) as a core technology for construction site security associated planning activities. The primary goal of 4D-BIM Safety research project is to improve the processes and use the BIM technology for safety design, management and communication as part of 4D construction. 
3D object modellers are used to virtually build real construction components. Objects thus created are imported into the project. Virtually a single object imported can used several times to represent various objects if they have similar shape and size. Four Virtual reality functions are identified: collision detection, terrain follow-up, geometry pick-up, and 3D tape measurement. These functions can provide a better walking environment, simulation of height related falls, object pick-up etc. [14] [61]

\section{DISCUSSIONS}

The discussion of the findings is based on the identified hazards and technologies which are applicable to that particular hazards from the existing literature.

\section{A. Identification of Hazards}

Hazard Identification is a method used to determine whether a specific circumstance, object, stuff etc. can have the potential to cause harm. The main goal of hazard detection is to classify and record the potential hazards that may be present at the workplace. Hazards are not identified based on the scale of the project, they are just identified on the basis of types. Falls, Stuck by Hazards, electrocution, cave in (trenching), caught - in or - between, etc. are common hazards that are categorized with different - different hazards falling under the categorized as well as common to different phases of the project. The studies which are undertaken to identify hazards suggests that they are identified in different stages of the projects as listed below:

1. During design and implementation.

2. Before tasks are done.

3. While tasks are being done.

4. During inspections

5. After incidents

According to the studies, construction hazards are found to be more in developing countries like India in comparison to developed countries. It is also discussed that there are 38 deaths per day takes place in construction sites in India which are much higher when compared to other countries. The remedies are also suggested in the past studies to ensure safety for the workers in construction sites.

\section{B. Identification of Technologies}

Identification of technologies is the process of evaluating that which technology is applicable to which hazards and which hazards can be stopped to occur by use of the existing and emerging technologies. The main aim of the identification of technologies is the identification of hazards beforehand and try to reduce the risk factor in the particular hazard and make the site environment workers friendly. The technology gives the strength to the workers belief as one is already aware about the hazard that can happen at the point of working which creates an intention to work more carefully and freely.

Technologies also helps in increasing the site productivity with the known facts and figures. According to studies, technological implementation to the sites, rapidly changesthe nature and environment of the site to ensure safety practices. It is also noticed from the studies that only $20 \%$ of workers are well known and well equipped with the technology from the workforce of 465 million construction workers in India [40] [41] [69]. Application of technology is an important way of maintaining health and protection at the construction site.Various technologies, such as sensor- based technology, information communication technology, radio frequency identification technology and virtual reality, are some of the tools and technologies that can be used to ensure construction safety both in India and in the world.

This paper gives the knowledge about the different types of existing technologies as well as the new and emerging technologies in construction in India as well as in the world which are used for safety.

\section{Implementation of Technology on Hazards}

Workplace safety is an essential part for any construction sites, as the workers or labours working in site wants safety and protection. It is also essential for any project owner or firms to complete the project without any hassle or problems which is only possible by implementation of the technology to hazards for the advance identification and get aware the risk areas. The technology allows the projects owners or project officials to work efficiently with the workers by providing them safety environment around them and by using these technologies will ultimately improves the productivity, quality, use of resources, etc. From the past studies, it is also inferred that technology can help to avoid life loss, wastage of resources, hazards, improper use of available resources, etc. The few points which were identified while going through the studies conducted in past are as follows:

1. Technology makes it easier for everyone to involve in the projects more quickly and more effectively with the safety precautions.

2. Technology allows the project managers to make more timely and informed decisions based on cost, labour and safety data available.

3. Technology simplifies and automates the information capturing data regarding safety and other aspects which are harmful for safety at construction sites.

4. Technology also helps teams at construction site to ensure safety and proceed towards the completion of the project quickly.

5. Technology allows the teams or workers to access various real time scenarios of the project hazards and helps them to cope with the emergency situations.

\section{CONCLUSION}

The working environment in construction practices is typically more dangerous than other sectors due to the use of heavy machinery, risky tools and hazardous substantial, each of which increases the potential for substantial accidents and injuries. Therefore, it is evident that there is a need for a focused commitment to safety in construction at all levels. It is clear from the above study of hazards that the reader gets a knowledge to apply which technologies to which hazard. The conclusive table is given below: 
Technological Aspects in Construction Safety with Applicability to Hazards in India

Table 1: Conclusive table of Technological Tools Used in Construction Industry for Hazard Prevention

\begin{tabular}{|c|l|c|c|c|c|c|}
\hline $\begin{array}{c}\text { Sl. } \\
\text { no: }\end{array}$ & \multicolumn{1}{|c|}{ Technological Tools } & Falls & Struck-by & $\begin{array}{c}\text { Electrocu } \\
\text { tion }\end{array}$ & $\begin{array}{c}\text { Caught-by } \\
\text { or in } \\
\text { between }\end{array}$ & References \\
\hline 1 & Smart vests & $\checkmark$ & $\checkmark$ & & $\checkmark$ & [1],[10],[18] \\
\hline 2 & Personalized safety instruction system & $\checkmark$ & $\checkmark$ & & $\checkmark$ & [8] \\
\hline 3 & Unmanned Arial Vehicles & $\checkmark$ & $\checkmark$ & & $\checkmark$ & [9],[13],[16] \\
\hline 4 & Dynamic Speed Display & & $\checkmark$ & & $\checkmark$ & [9] \\
\hline 5 & Delineation Devices & $\checkmark$ & $\checkmark$ & $\checkmark$ & $\checkmark$ & [9],[10],[12], \\
\hline 6 & Proximity Warning Systems & $\checkmark$ & $\checkmark$ & & $\checkmark$ & [9],[12],[16] [15],[16] \\
\hline 7 & Blind Spot Detection System & $\checkmark$ & $\checkmark$ & $\checkmark$ & $\checkmark$ & [10],[11],[12], [15], \\
\hline 8 & Real Time Location Tracking Systems & $\checkmark$ & & & & [16], [16] \\
\hline 9 & Body Posture Detection Systems & $\checkmark$ & & & & [10], [16] \\
\hline 10 & $\begin{array}{l}\text { Physiological Status Monitoring } \\
\text { systems }\end{array}$ & $\checkmark$ & & & & [10],[12], [15] \\
\hline 11 & Environmental Sensing Systems & $\checkmark$ & & & $\checkmark$ & [10] \\
\hline 12 & Micro Electro Mechanical Systems & $\checkmark$ & $\checkmark$ & & $\checkmark$ & [10] \\
\hline 13 & ANT+ wireless technology & $\checkmark$ & $\checkmark$ & & $\checkmark$ & [14], [16],[17] \\
\hline 14 & 4D- BIM and Virtual Reality Systems & $\checkmark$ & $\checkmark$ & $\checkmark$ & & $\checkmark$ \\
\hline
\end{tabular}

\section{RESULT ANALYSIS}

The purpose of this study was to investigate the technological aids that are available, to tackle the hazards that are prevalent in the construction industry using literature review. The findings of the study have been summarised and represented in Table 1.

From the conclusive table we can see that most of the technologies identified can effectively prevent the fall, struck-by and caught-in or -between hazards. This is because these technologies use sensors as well as visual aids to identify the relative positions of the workers with respect to the location of equipment or hazard prone area and alert them well before the risk arises. At the same time, it is evident from the table that the technological interventions to tackle the hazards due to electrocution is limited. As discussed above electrocution hazards occur mainly due to faulty electrical equipment. In order to intercept these hazards, the along with the sensors to identify and notify the workers of their position, sensors or alarms that can identify, the faulty equipment as well as the potential equipment that can cause electrocution, have to be developed.

From the study it is also evident that the integration and combination of many of these technological tools can also effectively prevent hazards in construction sites. For example, if we could combine the proximity tracking system, physiological status monitoring systems, real time location tracking systems and similar technological interventions and implement them in the Personal Protective Equipment, such as safety vests or in form of wearable technology, it would me more effective to collect the data on site and alert the stakeholders before the accidents. [1, 10 , 18]

\section{REFERENCES}

[1] Shah, D., Chheda, S., Mehta, S., \& Hirani, V. (2017). Construction Safety in Indian Scenario and Technological Advancements in Safety Tracking. International Research Journal of Engineering and Technology (IRJET) , 1789-1794.
[2] OSHA. (2018). Occupational Safety and Health Administration. Retrieved from Commonly Used Statistics: https://www.osha.gov/data/commonstats

[3] OSHA. (2011). Construction Focus Four: Fall Hazards, Instructors Guide. OSHA Directorate of Training and Education.

[4] Huang, X., \& Hinze, J. (2003). Analysis of Construction Worker Fall Accidents. Journal of Construction Engineering and Management, 129(3), 262-271.

[5] OSHA. (2011). Construction Focus Four: Struck-By Hazards, Instructors Guide. OSHA Directorate of Training and Education.

[6] OSHA. (2011). Construction Focus Four: Electrocution, Instructors Guide. OSHA Directorate of Training and Education.

[7] OSHA. (2011). Construction Focus Four: Caught-In or -Between, Instructors Guide. OSHA Directorate of Training and Education.

[8] Tang, N., Hu, H.,Xu, F.,\&Zhu, F. (2019). Personalized safety instruction system for construction site based on internet. Safety Science, 161-169.

[9] Nnaji, C.,Gambatese, H., Lee, H.W., \&Zhang, F. (2019). Improving construction work zone safety using technology: A systematic review of applicable technologies. Journal of Traffic and Transportation Engineering (English Edition).

[10] Awolusi, I., Marks, E.,\&Hallowell, M. (2017). Wearable technology for personalized construction safety monitoring and trending: Review of applicable devices. Automation in Construction, 96-106.

[11] Lim, J. S., Song, K. I., \& Lee, H. L. (2016). Real-Time Location Tracking of Multiple Construction Laborers. Sensors (Basel, Switzerland), 16(11), 1869. https://doi.org/10.3390/s16111869

[12] Skibniewski, M. J. (2014). Information technology applications in construction safety assurance. Journal of Civil Engineering and Management, 778-794

[13] Irizarry, J.,Gheisari, M., \& Walker B. N. (2012) Usability assessment of drone technology as safety inspection tools, Journal of Information Technology in Construction (ITcon), Vol. 17, pg. 194-212

[14] Sulankivi, K., Kähkönen, K., Mäkelä, T., \&Kiviniemi, M. (2010). 4DBIM for Construction Safety Planning. In P. Barrett, D. Amaratunga, R. Haigh, K. Keraminiyage, \& C. Pathirage (Eds.), CIB 2010 World Congress proceedings

[15] Chae, S., \& Yoshida, T. (2010) Application of RFID Technology to Prevention of Collision Accident with Heavy Equipment. Automation in Construction, 19, 368-374. http://dx.doi.org/10.1016/j.autcon.2009.12.008

[16] Hadikusumo, B.H.W., \&Rowlinson, S. (2002). Integration of virtually real construction model and design-for-safety-process database. Automation in Construction, 501-509.

Published By:

Blue Eyes Intelligence Engineering \& Sciences Publication

(C) Copyright: All rights reserved.

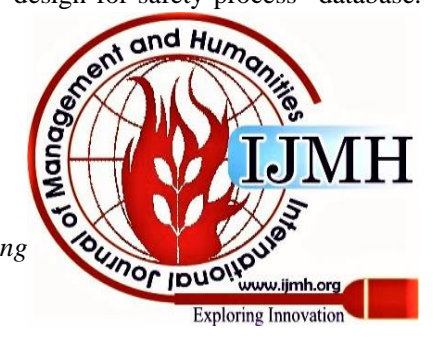


[17] Zhao, D., Thabet, W., McCoy, A., \& Kleiner, B. (2012). Managing electrocution hazards in the US construction industry using VR simulation and cloud technology. 759-764. 10.1201/b12516-120.

[18] Clarke, T. (n.d.). Wearable Technology That Will Change the Construction Industry. Retrieved from Safety Culture: https://blog.safetyculture.com/industry-trends/wearable-technologythat-will-change-the-construction-industry

[19] https://www.makeinindia.com/sector/ construction

[20] https://www.ccohs.ca/oshanswers/ hsprograms/hazard_identification.html

[21] https://www.mydatascope.com/blog/en/ technology-to-improve-workplace-safety/

2019/01/08/how-to-use-

[22] https://www.sbci.com/technology-can-improve-constructionefficiency/

[23] https://www.femoran.com/hvac-plumbing-construction-blog/smartvests-keep-construction-workers-safe

[24] https://austintexas.gov/sites/default/files/ files/DSDD_FAQs.pdf

[25] https://www.rms.nsw.gov.au/business-industry/partners suppliers/documents/technicalmanuals/delineation/delineationsect1v11_i.pdf

[26] https://www.researchgate.net/publication/ tiple_Construction_Laborers

[27] https://web.wpi.edu/Pubs/E_project/Available/E-project-022819 104135/unrestricted/Fall_Detection_and_Posture_Monitoring_System .pdf

[28] https://patents.google.com/patent/ US20120029299A1/en

[29] https://pdfs.semanticscholar.org/cd88/ 92ca74e2203606b096467aa44e42cbb1b26b.pdf

[30] https://eprints.qut.edu.au/102135/3/ 102135.pdf

[31] Michael Charles, J. P. (2007). Guide to Best Practice for Safer Construction: Literature Review 'From concept to completion'. Cooperative Research Centre for Construction Innovation.

[32] Suárez Sánchez, F. A., Carvajal Peláez, G. I., \&CataláAlís, J. (2017). Occupational safety and health in construction: a review of applications and trends. Industrial health, 55(3), 210-218. https://doi.org/10.2486/indhealth.2016-0108

[33] Skeepers, N.C. \&Mbohwa, C. 2016. Literature review : improving health and safety in the construction industry through cultural transformation. Industrial Engineering and Operations Management Conference, Detroit, Michigan, 23- 25 September 2016..

[34] Revathi K., Ezhilmathi P., Manoj Kumar R., Sivaranjani M., \& Devaki R. (2017). Safety Issues, Problems and Recommendations to Research in Science, Engineering and Technology, 20890-20896.

[35] Zhao, T., Kazemi, S., Liu, W., \& Zhang, M. (2018). The Last Mile: Safety Management Implementation in Construction Sites. Advances in Civil Engineering, 2018, 1-15. doi: 10.1155/2018/4901707

[36] Subramani, T., \&Lordsonmillar, R. (2014). Safety Management Analysis in Construction Industry. International Journal of Engineering Research and Applications, 117-120.

[37] Hamid, A.R.A\&Majid, M.Z.A. (2006). Construction Safety Benchmarking. 10.13140/2.1.1274.1769.

[38] Huebschman, C.R.,Gracia, C., Bullock, D.M., \& Abraham, D.M (2002). Construction Work Zone Safety. INDOT Research.

[39] Srivastava, R. S., \& Jha, A. (2016). Capital and Labour Standards in the Organised Construction Industry in India, A Study Based on Fieldwork in the National Capital Region of Delhi. New Delhi: Centre for the Study of Regional Development, Jawaharlal Nehru University.

[40] Nottath, M. N. (n.d.). Health and Safety Management on Construction Sites in India. Sri Krishna College of Technology.

[41] Huang, X., \& Hinze, J. (2006). Owner's Role in Construction Safety. Journal of Construction Engineering and Management, 164-173.

[42] Kanchana, S., Sivaprakash, P., \& Joseph, S. (2015). Studies on Labour Safety in Construction Sites. Hindawi Publishing Corporation- The Scientific World Journal.

[43] Li, R. Y., \& Poon, S. W. (2013). A Literature Review on the Causes of Construction Accidents. Construction Safety, Risk Engineering.

[44] Mehra, C., Hussain, S. M., \& Fatima, A. (2016). Importance of Safety in Indian Construction. 5th International Conference on Recent Trends in Engineering, Svience and Management, (pp. 461-468). Pune.

[45] Bilal, M. (n.d.). Building and Construction Accident Statistics.

[46] Singh, K. (2014). Safety in Indian Construction. International Journal of Engineering Research \& Technology (IJERT), 1564-1566.

[47] Saeed, Y. S. (2017). Safety Management in Construction Projects Journal of University Of Duhok, 546-560.

[48] The construction industry in the twenty-first century: Its image, Labour Organisation. Geneva. Indian Construction Industry. International Journal of Innovative employment prospects and skill requirements. (2001). Interntional

[49] Hale, Andrew. (2009). Why safety performance indicators?. Safety Science. 47. 479-480. 10.1016/j.ssci.2008.07.018.

[50] Karan Singh (2014) "Safety in Indian Construction" International Journal of Engineering Research \& Technology (IJERT) ISSN: 2278 0181 IJERTV3IS111031 (This work is licensed under a Creative Commons Attribution 4.0 International License.) Vol. 3 Issue 11, November.

[51] Charles, M., Pillay, J., \& Ryan, R. (2007). Guide to Best Practice for Safer Construction: Literature review 'From concept to completion'. Australia: Cooperative Research Centre for Construction Innovation.

[52] Sah, R., \& Hussain, S. A. (2019). Safety Aspects in the Construction Industry. International Journal of Engineering Research ansTechnology..

[53] Patel, D A and Jha, K N (2016), an Estimate of Fatal Accidents in Indian Construction. In: P W Chan and C J Neilson (Eds.) Proceedings of the 32nd Annual ARCOM Conference, 5-7 September 2016, Manchester, UK, Association of Researchers in Construction Management, Vol 1, 539-548.

[54] Patel, D A (2015) "Estimating The Number of Fatal Accidents and Investigating The Determinants Of Safety Performance in Indian Construction", PhD thesis, Indian Institute of Technology Delhi, New Delhi, India.

[55] Sonje, R. U., \&Borde, S. V. (2014). Micro-Electromechanical Systems (Mems). International Journal of Modern Engineering Research (IJMER), 102-105.

[56] Howard, J., Murashov, V., \&Branche, C. M. (2017). Unmanned aerial vehicles in construction and worker safety. American Journal of Industrial Medicine, 3-10.

[57] Chakrabarti, D. (2013). Construction Industries in India Some Facts \& Figures. Construction Workers Federation of India.

[58] http://www.rta.nsw.gov.au/ doingbusinesswithus/downloads/technicalmanuals/delineation_dl1.ht $\mathrm{ml}$

[59] http://www.austintexas.gov/ department/dynamic-speed-displaydevices

[60] Shumway, H. E., Naeem, S., \& Jin, Y. (2019). Fall Detection and Posture Monitoring System. Retrieved from https://digitalcommons.wpi.edu/mqp-all/6752

[61] Hadikusumo, B., \&Rowlinson, S. (2002). Integration of virtually rea construction model and design-for-safety-process database. Automation in Construction, 501-509.

[62] Azmy, Nurhidayah\&Mohd Zain, Ahmad Zairi. (2016). The application of technology in enhancing safety and health aspects on malaysian construction projects. Journal of Engineering and Applied Sciences. 7209-7213

[63] Ministry of Labour and Employment, India. (2011). Report of the Working Group on Occupational Safety and Health for the 12th Five Year Plan, 2012-2017. Government of India.

[64] Lee, W., \&Migliaccio, G. C. (2014). Field Use of Physiological Status Monitoring (PSM) to Identify Construction Workers' Physiologically Acceptable Bounds and Heart Rate Zones. International Conference on Computing in Civil and Building Engineering (pp. 1037-1044) Orlando: American Society of Civil Engineers.

[65] Ministry of Labour and Employment, India. (2018). Pradhan Mantri RojgarProtsahan Yojana, Annual Report, 2018-2019. Government of India.

[66] Tsai, M.-K. (2017). Applying physiological status monitoring in improving construction safety management. KSCE Journal of Civil Engineering, 2061-2066.

[67] Zhipeng Zhou, Javier Irizarry \&Qiming Li (2013) Applying advanced technology to improve safety management in the construction industry: a literature review, Construction Management and Economics, 31:6, 606-622

[68] Awolusi, Ibukun \& Nnaji, Chukwuma \& Marks, Eric \& Hallowell, Matthew. (2019). Enhancing Construction Safety Monitoring through the Application of Internet of Things and Wearable Sensing Devices: A Review. 530-538. 10.1061/9780784482438.067.

[69] https://www.britsafe.org/about-us/press-releases/2019/the-future-ofhealth-and-safety-in-india/

Published By: 


\section{AUTHORS PROFILE}

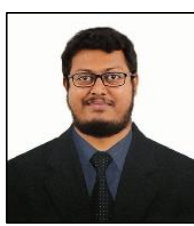

Abhay Malik, received B.Sc. (IT) degree from H.N.B.GharwalUniversity, Uttarakhand, India in 2012 and B. Arch. Degree from Dr. A.P.J Abdul Technical University, Uttar Pradesh, India in 2018. He is currently pursuing his Masters Degree in Building Engineering and Management from School of Planning and Architecture, Vijayawada, Andhra Pradesh, India. From 2018 to 2019, he was one of the Principal Architect of his own firm Acquaint Architects. Currently, he is a post-graduation student furnishing his skills in the field of management and building engineering.

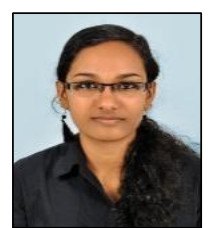

Sripadma Sanjiv E, graduated with her B.Arch degree from Government Rajiv Gandhi Institute of Technology, Kottayam, Kerala under Mahatma Gandhi University, Kottayam, Kerala, India in 2017. She practiced as a Junior Architect in an Architectural firm at Calicut, Kerala from 2017 to 2019. Currently she is pursuing her Masters degree in Building Engineering and Management at School of Planning and Architecture, Vijayawada, Andhra Pradesh, India.

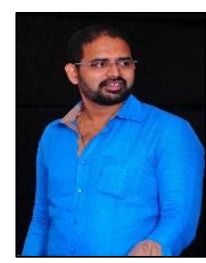

Kranti Kumar Myneni, received B.Arch degree from JNTU, Hyderabad, Telangana, India in 2001 and pursed Masters (M.Sc. - Construction Management) from South Bank University, London in 2003. Currently working as Assistant Professor in School of Planning Architecture Vijayawada. Member of Council of Architecture and Fellow member of Indian Institute of Architects.

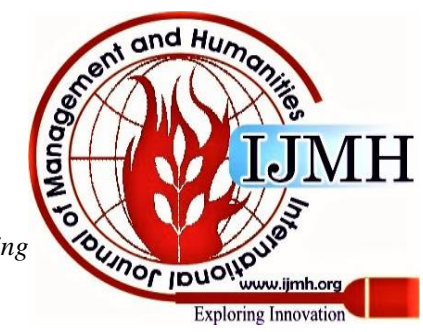

